\title{
Dilute Solution Properties of Random Acrylonitrile/ Methyl Acrylate Copolymer
}

\author{
Kenji KAMIDE, ${ }^{*}$ Yukio MIYAZAKI, ${ }^{*}$ \\ and Hidehiko KoBAYASHI** \\ *Textile Research Laboratory, Asahi Chemical Industry Company, Ltd., \\ Takatsuki, Osaka 569, Japan \\ ** Research and Development Administration, Asahi Chemical Industry Company, Ltd., \\ Hibiya, Tokyo 100, Japan
}

(Received January 29, 1982)

\begin{abstract}
A copolymer of acrylonitrile (AN) and methyl acrylate (MA) was prepared by use of a redox catalyst and was separated into 16 fractions by successive solution fractionation, using dimethyl sulfoxide as the solvent and toluene as the precipitant. Except for the first few, all fractions had essentially the same composition: $92 \pm 0.5$ weight percent in AN. Viscosity, light scattering and osmotic pressure were measured for these fractions in dimethylformamide (DMF), an ethylene carbonate (EC)/water mixture containing $82.5 \mathrm{wt} \% \mathrm{EC}$, and aqueous nitric acid of various compositions. This $\mathrm{EC} /$ water mixture at $25^{\circ} \mathrm{C}$ and $51 \mathrm{wt} \%$ aqueous nitric acid at $25^{\circ} \mathrm{C}$ were found to be Flory's theta solvents for the AN/MA copolymer with $92 \mathrm{wt} \%$ AN. The MarkHouwink-Sakurada equations for this polymer were $[\eta]=2.13 \times 10^{-2} M_{w}^{0.74}$ in DMF, $[\eta]=0.152$ $M_{w}^{0.50}$ in the EC/water mixture, and $[\eta]=0.215 M_{w}^{0.50}$ in $51 \mathrm{wt} \%$ aqueous nitric acid, all at $25^{\circ} \mathrm{C}$. The molecular weight dependence of the radius of gyration $\left\langle S^{2}\right\rangle_{z}^{1 / 2}$ in DMF at $25^{\circ} \mathrm{C}$ was represented by $\left\langle S^{2}\right\rangle_{z}^{1 / 2} / \mathrm{cm}=2.13 \times 10^{-9} M_{w}^{0.58}$. Flory's viscosity parameter $\Phi$ was found to be $2.5 \times 10^{23}$ in DMF at $25^{\circ} \mathrm{C}$ and $2.9 \times 10^{23}$ in the EC/water mixture at $25^{\circ} \mathrm{C}$. The unperturbed chain dimensions $A$ determined by both thermodynamic and hydrodynamic methods were 0.93 in DMF, 0.86 in the EC/ water mixture, and 1.11 in $55 \mathrm{wt} \%$ aqueous nitric acid, all at $25^{\circ} \mathrm{C}$, in units of $10^{-8} \mathrm{~cm}$.

KEY WORDS Acrylonitrile-Methyl Acrylate Copolymer / Theta Solvent / Unperturbed Chain Dimension / Nitric Acid / Ethylene Carbonate / Dimethylformamide / Mark-Houwink-Sakurada Equation /
\end{abstract}

Since the time Du Pont Company first commercialized an acryl fiber in 1948, the commercially available product of this fiber consisted of acrylonitrile (AN) and methyl acrylate (MA) monomers. Over the years there have been virtually no reports on the molecular characterization of the acrylonitrile and methyl acrylate copolymer (AN/MA copolymer) with a composition suitable for use as a synthetic fiber. The only exception is the measurement of the molecular weight distribution of AN/MA copolymer by gel-permeation chromatography. ${ }^{1}$

Nakayama et al. ${ }^{2}$ found that the packing of polymer chains in the amorphous region of a membrane or fiber made from a solution of polyacrylonitrile (PAN) was loose or dense, depending on whether the solvent was dimethylformamide
(DMF) or aqueous nitric acid. Thus, it can be expected that the dissolved state of PAN has effect on the structure of the solid coagulated from the solution.

The present paper reports some typical solution properties of the AN/MA copolymer of fixed composition $\left(\mathrm{AN} / \mathrm{MA}=91.5: 8.5\right.$ by $\mathrm{wt}^{\mathrm{o}} \%$ ) in $\mathrm{DMF}$ a mixture of ethylene carbonate (EC) and water, and aqueous nitric acid of various compositions.

\section{EXPERIMENTAL}

\section{Polymer}

A sample of AN/MA copolymer was prepared in water by conventional free-radical polymerization at $55^{\circ} \mathrm{C}$ using a redox catalyst (ammonium persulfate and ammonium hydrogen sulfite) as the 
initiator. The copolymer prepared has a weightaverage molecular weight $M_{w}$ of $13.7 \times 10^{4}$ and was found to have the following composition of acrylonitrile (AN) and methyl acrylate (MA) when determined by ${ }^{1} \mathrm{H}-\mathrm{NMR}$ analysis (details will be given later): $\mathrm{AN} 91.5 \mathrm{wt} \%$, MA $8.5 \mathrm{wt} \%$. In the radical polymerization of an AN/MA copolymer, the monomer reactivity ratios for $\mathrm{AN}$ and MA radicals are $1.0 \pm 0.3,{ }^{3}$ so that random copolymers may be obtained from AN and MA monomers. If we define $P_{2}(i j)$ as the number fraction of $i-j$ diads, we obrain $P_{2}(\mathrm{AN} \mathrm{AN}) \simeq 0.91, P_{2}(\mathrm{MA} \mathrm{MA}) \simeq 0.01$ and $P_{2}(\mathrm{AN} \mathrm{MA})+P_{2}(\mathrm{MA} \mathrm{AN}) \simeq 0.08$. Yamadera and Murano $^{4}$ showed that PAN prepared by conventional redox polymerization is $50 \%$ syndiotactic and $50 \%$ isotactic (i.e., atactic). Therefore, the AN/MA copolymer prepared in this study is expected to be nearly atactic.

\section{Solvent}

Reagent grade dimethylformamide (DMF), ethylene carbonate (EC) and $80 \mathrm{wt} \%$ nitric acid, all highly polar, were used as received. For the fractionation, analytical chemical grade dimethyl sulfoxide (DMSO) and toluene were used. Aqueous solvents of 67,55 , and $51 \mathrm{wt} \%$ nitric acid were prepared by adding distilled water to $80 \mathrm{wt} \%$ nitric acid.

\section{Fractionation}

In this study, the successive solution fractionation $(\mathrm{SSF})^{5}$ was employed using DMSO as a solvent and toluene as a precipitant. In mixtures of these two liquids, complete liquid-liquid phase separation occurred and the polymer-lean phase could be readily isolated from the polymer-rich phase. A $1.0 \mathrm{wt} \%$ solution of the whole polymer $(120 \mathrm{~g})$ in DMSO was separated into 16 fractions of almost equal amounts by adding toluene to the solution at $30^{\circ} \mathrm{C}$. Each fraction was analyzed for composition with a ${ }^{1} \mathrm{H}$ NMR spectrometer model PMX 60 (60 MHz, JOEL, Japan) deuterated dimethylsulfoxide DMSO- $d_{6}$. The MA content was calculated from resonance intensities of methylene $(2.1 \mathrm{ppm})$ and methyl (3.7 ppm) groups in the NMR spectra. The first three fractions had a MA content somewhat higher than others. Hence, the remaining 11 fractions in which the MA content was distributed in a very narrow range of $8.0 \pm 0.5 \mathrm{wt} \%$ were chosen for the present study. These fractions ranged in weight-average molecular weight $M_{w}$ from $4 \times 10^{4}$ to $53 \times 10^{4}$.

\section{Solution Viscosity}

Viscosity measurements in DMF, an ethylene carbonate/water (EC/water) mixture with the EC composition of $82.5 \mathrm{wt} \%$, and aqueous nitric acid $\left(\mathrm{HNO}_{3}\right)$ were made with modified Ubbelohde suspension-type viscometers in a bath thermostated within $\pm 0.01^{\circ} \mathrm{C}$. The copolymer was dissolved in $\mathrm{DMF}$ and in the $\mathrm{EC} /$ water mixture at $50^{\circ} \mathrm{C}$. Great care was taken in dissolving the polymer in nitric acid to avoid the decomposition of the polymer and the solvent. Thus, the copolymer was dissolved in nitric acid at $5^{\circ} \mathrm{C}$, and all the viscosity measurements on the resulting solutions were carried out at $5^{\circ} \mathrm{C}$ and $25^{\circ} \mathrm{C}$ within $1 \mathrm{~h}$ following dissolution. The polymer in the EC/water mixture was stored at $30^{\circ} \mathrm{C}$, since the solution tended to crystallize during a long standing below $25^{\circ} \mathrm{C}$.

\section{Light Scattering}

Light scattering measurements were made in $\mathrm{DMF}$, the EC/water mixture and aqueous nitric acid. A Shimadzu-Brice type light scattering photometer PG-21 and a FICA model photogoniodiffusiometer were used for the first two solvents and the last solvent, respectively.

\section{(a) $D M F$}

Each fraction was dissolved in DMF at $50^{\circ} \mathrm{C}$ to make a $0.3 \mathrm{wt} \%$ solution. The solution was centrifuged at $2 \times 10^{4} \mathrm{~g}$ for $70 \mathrm{~min}$ in a Hitachi model $55 \mathrm{p}$ 7 automatic preparative ultracentrifuge. The upper two-thirds of the supernatant phase were carefully sucked up with a microsyringe. Four concentrations were prepared by diluting the solution with pure DMF, and then each solution was filtered through a Sartorius membrane filter $0.15 \mu \mathrm{m}$ (SM-11608) and directly transferred into the cylindrical light scattering cell.

The specific refractive index increment $\mathrm{d} n / \mathrm{d} C$ for the AN/MA copolymer in DMF was determined to be $0.077 \mathrm{~cm}^{3} \mathrm{~g}^{-1}$ by a Shimadzu differential refractometer model DR- 4 at $25^{\circ} \mathrm{C}$ and for a wavelength $\lambda_{0}$ of $546 \mathrm{~nm}$.

Vertically polarized light of wavelength $\lambda_{0}=$ $546 \mathrm{~nm}$ was used as the incident beam, and the unpolarized scattering intensity was measured at various angles from 30 to $150^{\circ}$. The Rayleigh ratio was denoted by $R_{\mathrm{U}}^{\mathrm{u}}(\theta)$ ( $\theta$ is scattering angle). Very 
slight fluorescence was observed in DMF solutions of most of the polymer fractions. The correction of the measured intensity for fluorescence was made according to the method by Kamide et al. ${ }^{6}$ The apparatus was calibrated with benzene (Rayleigh ratio $R_{\mathrm{U}}^{\mathrm{u}}(\theta)=16.3 \times 10^{-6}$ at $\left.\lambda_{0}=546 \mathrm{~nm}\right)$. The effect of the chemical composition distribution on scattering intensity was neglected, and the data obtained were analyzed according to the procedure described in a previous paper. ${ }^{6}$

\section{(b) EC/Water Mixtures}

Six EC/water mixtures of EC content $w_{\mathrm{e}}=80,81$, $81.5,82.5,85$, and $87.5 \mathrm{wt} \%$ were prepared, and the AN/MA copolymer fractions were dissolved at $50^{\circ} \mathrm{C}$. The solutions were filtered through a Fluoro pore filter (mean pore size $0.1 \mu \mathrm{m}$; manufactured by Sumitomo Denko Ltd.) and transferred into the measuring cell at $30^{\circ} \mathrm{C}$.

Unpolarized light of wavelength $\lambda_{0}=546 \mathrm{~nm}$ was used, and the unpolarized scattering intensity was measured (the Rayleigh ratio in this case is denoted by $R_{\mathrm{U}}^{\mathrm{u}}(\theta)$ ). For a polymer dissolved in a binary mixture, $R_{\mathrm{U}}^{\mathrm{u}}(\theta)$ is related to $M_{w}$ by the equation ${ }^{7}$

$$
\frac{K_{\mathrm{L}} C}{R_{\mathrm{U}}^{\mathrm{u}}(\theta)}=\frac{1}{M_{w} P(\theta)}+2 A_{2, \mathrm{~L}} C+\cdots
$$

where

$$
K_{\mathrm{L}}=\frac{2 \pi^{2} n_{0}{ }^{2}}{\lambda_{0}^{4} N_{\mathrm{A}}}\left(\frac{\mathrm{d} n}{\mathrm{~d} C}\right)_{w_{\mathrm{e}}}^{2}\left\{1+\xi_{\mathrm{a}} \frac{\left(\frac{\mathrm{d} n_{0}}{\mathrm{~d} w_{\mathrm{e}}}\right)}{\left(\frac{\mathrm{d} n}{\mathrm{~d} C}\right)_{w_{\mathrm{e}}}}\right\}^{2}
$$

and

$$
P(\theta)=1-\frac{1}{3}\left\langle S^{2}\right\rangle_{z}\left(\frac{4 \pi n_{0}}{\lambda_{0}}\right)^{2} \sin ^{2} \theta / 2+\cdots
$$

Here, $C$ is the polymer concentration $\left(\mathrm{g} \mathrm{cm}^{-3}\right), A_{2, \mathrm{~L}}$ is the second virial coefficient, $n_{0}$ is the refractive index of the solvent, $N_{\mathrm{A}}$ is Avogadro's constant, $(\mathrm{d} n / \mathrm{d} C)_{w_{\mathrm{e}}}$ is the refractive index increment of the polymer solution at a constant composition $w_{\mathrm{e}}, \mathrm{d} n_{0} /$ $\mathrm{d} w_{\mathrm{e}}$ is the refractive index increment of the binary mixture, $\left\langle S^{2}\right\rangle_{z}$ is the $z$-average mean-square radius of gyration, and $\xi_{\mathrm{a}}$ is the preferential adsorption parameter $\left(\equiv-\mathrm{d} w_{\mathrm{e}} / \mathrm{d} C\right)$. For the EC $(82.5 \mathrm{wt} \%)$ and water $(17.5 \mathrm{wt} \%)$ mixture, $(\mathrm{d} n / \mathrm{d} C)_{w_{\mathrm{e}}}$ was 0.111 $\mathrm{cm}^{3} \mathrm{~g}^{-1}$ and $\left(\mathrm{d} n_{0} / \mathrm{d} w_{\mathrm{e}}\right)$ was 0.085 .

Owing to the experimental difficulty in determining $\xi_{\mathrm{a}}$, the constant $K_{\mathrm{L}}$ was evaluated by substituting the experimental value of $\left(C / R_{\mathrm{U}}^{\mathrm{u}}(\theta)\right)_{c \rightarrow 0}$ for
EC/water mixture and the $M_{w}$ value obtained in DMF into eq 1. The value of $K_{\mathrm{L}}$ so determined were $(0.97 \pm 0.02) \times 10^{-7}$ for the EC/water mixtures with $w_{\mathrm{e}}=81.5-87.5 \mathrm{wt} \%$. This procedure for estimating $K_{\mathrm{L}}$ is reasonable, provided that the AN/MA copolymer does not associate or decompose in the EC/water mixture, at least during the period of each light scattering measurement. For the AN/MA copolymer in the EC/water mixture with $w_{\mathrm{e}}=80 \mathrm{wt} \%$ at $25^{\circ} \mathrm{C}$ the scattering intensity increased markedly with time. This implies that the polymer precipitated in the EC/water mixture with $w_{\mathrm{e}}=80 \mathrm{wt} \%$. At $w_{\mathrm{e}}=81 \mathrm{wt} \%$ and $C=4.82 \times$ $10^{-4} \mathrm{~g} \mathrm{~cm}^{-3}$ no precipitation occurred at $25^{\circ} \mathrm{C}$ for $1 \mathrm{~h}$, but in the same mixture with $C>2.08 \times$ $10^{-3} \mathrm{~g} \mathrm{~cm}^{-3}$ precipitation began very shortly after the solution was cooled down to $25^{\circ} \mathrm{C}$. In the $\mathrm{EC} /$ water mixtures with EC contents not lower than $81.5 \mathrm{wt} \%$, neither crystalization nor precipitation of the polymer took place for at least several hours. Using the $K_{\mathrm{L}}$ value estimated by the method mentioned above, $\left\langle S^{2}\right\rangle_{z}$ and $A_{2, \mathrm{~L}}$ were determined by eq 1 and 3. $\xi_{\mathrm{a}}=0.048$ was obtained for the EC/water mixture with $w_{\mathrm{e}}=82.5$ $\mathrm{wt} \%$ by putting $K_{\mathrm{L}}=0.97 \times 10^{-7}, \quad n_{0}=1.409$, $(\mathrm{d} n / \mathrm{d} C)_{w_{\mathrm{e}}}=0.111 \mathrm{~cm}^{3} \mathrm{~g}^{-1}$ and $\left(\mathrm{d} n_{0} / \mathrm{d} w_{\mathrm{e}}\right)=0.085$ into eq 2. This small value of $\xi_{\mathrm{a}}$ suggests that $\mathrm{EC}$ is not preferentially adsorbed on the AN/MA copolymer.

(c) Aqueous Nitric Acid

For the determination of the radii of gyration $\left\langle S^{2}\right\rangle_{z}^{1 / 2}$ of the AN/MA copolymers in aqueous nitric acid (nitric acid content $w_{n}=51,55,56$, and 80 $\mathrm{wt} \%$ ), it was again assumed that the $M_{w}$ values measured in DMF could be obtainable in nitric acid. Since nitric acid is very corrosive, a cylindrical glass cell with a round bottom was employed. Since aqueous nitric acid has a very complicated concentration, ${ }^{8}$ the $K_{\mathrm{L}}$ value in this solvent was estimated in the same manner used for the EC/water mixtures. The values obtained were 1.16, 1.14, 1.07, and 1.02 in units of $10^{-7}$ for $51,55,67$, and $80 \mathrm{wt} \%$ nitric acid, respectively. The values of $\left\langle S^{2}\right\rangle_{z}^{1 / 2}$ in aqueous nitric acid were determined by these $K_{\mathbf{L}}$ values.

Osmotic pressure measurements were carried out with a Hewlett Packard high speed membrane osmometer model 502 in DMF at $25^{\circ} \mathrm{C}$. The membrane was a Sartorius SM 115 membrane. No leakage of the solute through the membrane was 
K. Kamide, Y. MiYaZAKI, and H. Kobayashi

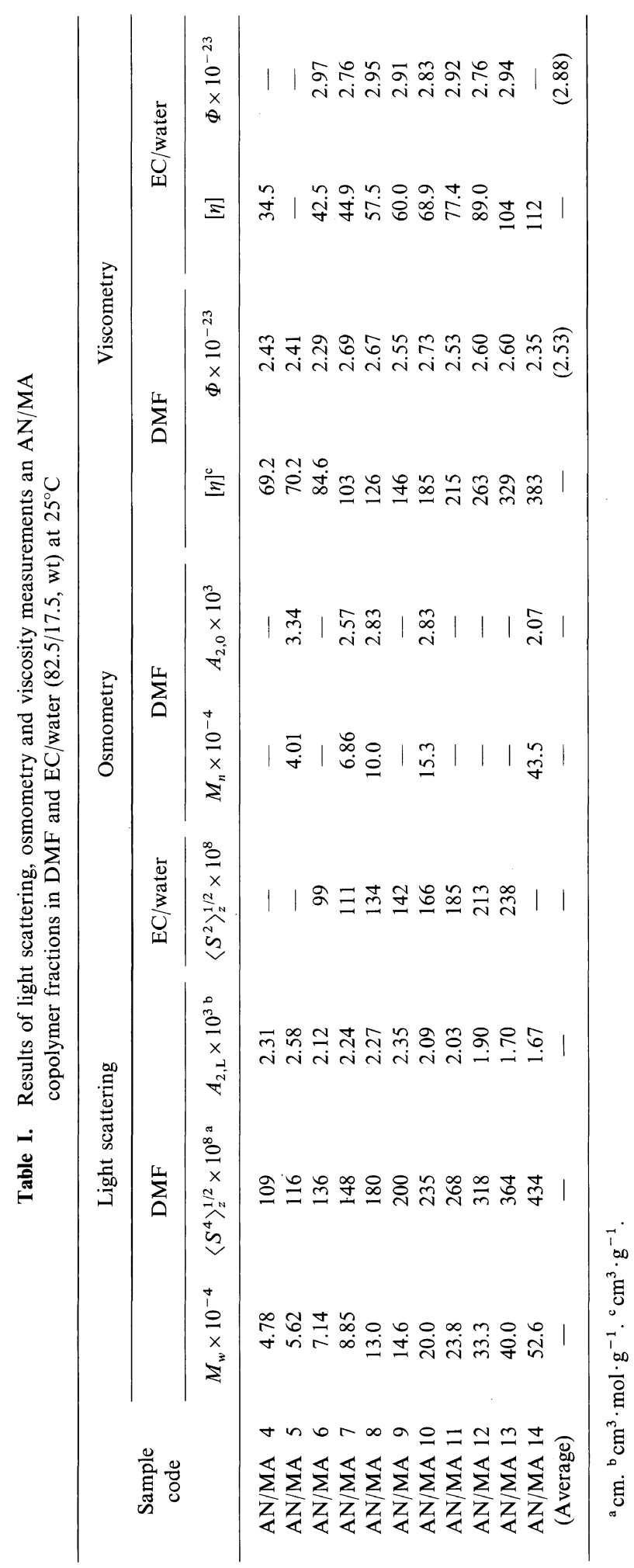


detected. The straight lines were obtained between $\Pi / C$ ( $\Pi=$ osmotic pressure $)$ and $C$. The numberaverage molecular weight $M_{n}$ and second virial coefficient $A_{2,0}$ (the subscript zero means osmometry) were determined in the conventional way.

\section{RESULTS AND DISCUSSION}

A typical Zimm plot for the AN/MA copolymer in DMF at $25^{\circ} \mathrm{C}$ is shown in Figure 1. Table I lists $M_{w}, M_{n},\left\langle S^{2}\right\rangle_{z}^{1 / 2}, A_{2, \mathrm{~L}}, A_{2,0}$ and the limiting viscosity number $[\eta]$ for eleven AN/MA copolymer fractions in DMF at $25^{\circ} \mathrm{C}$. The table also contains the data for $\left\langle S^{2}\right\rangle_{z}^{1 / 2}$ and $[\eta]$ in the EC/water mixture with $w_{\mathrm{e}}=82.5 \mathrm{wt} \%$. Table II compiles $\left\langle S^{2}\right\rangle_{z}^{1 / 2}$ and $[\eta]$ in aqueous nitric acid, respectively.

Figure 2 shows the plot of $\left(C / R_{\mathrm{U}}^{\mathrm{u}}(\theta)\right)_{\theta \rightarrow 0}$ against $C$ for two AN/MA copolymer fractions with $M_{w}=$ $20 \times 10^{4}$ and $33.3 \times 10^{4}$ in $\mathrm{EC} /$ water mixtures of various compositions. The slope of the plot allows $A_{2}$ to be evaluated if it is assumed that $K_{\mathrm{L}}$ in eq 1 is independent of $w_{\mathrm{e}}$. The $A_{2}$ values obtained on this assumption are plotted against $w_{\mathrm{e}}$ in Figure 3, each $A_{2}$ of these two fractions is zero at $w_{\mathrm{e}}=82.5 \mathrm{wt} \%$ and slightly negative at $w_{\mathrm{e}}=81.5 \mathrm{wt} \%$. This indicates that the $\mathrm{EC} /$ water mixture of $w_{\mathrm{e}}=82.5 \mathrm{wt} \%$ at $25^{\circ} \mathrm{C}$ is a Flory's theta solvent for the AN/MA copolymer.

In order to find Flory's theta conditions with aqueous nitric acid, $A_{2, \mathrm{~L}}$ for the AN/MA copolymer fraction with $M_{w}=23.8 \times 10^{4}$ is plotted as a function of nitric acid concentration as shown in Figure 4. In this figure, the values of the long-range

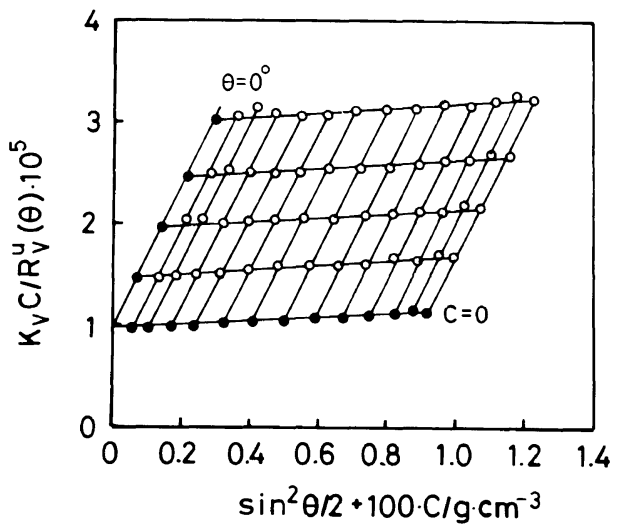

Figure 1. A typical Zimm plot for AN/MA fraction 8 in $\mathrm{DMF}$ at $25^{\circ} \mathrm{C}$.

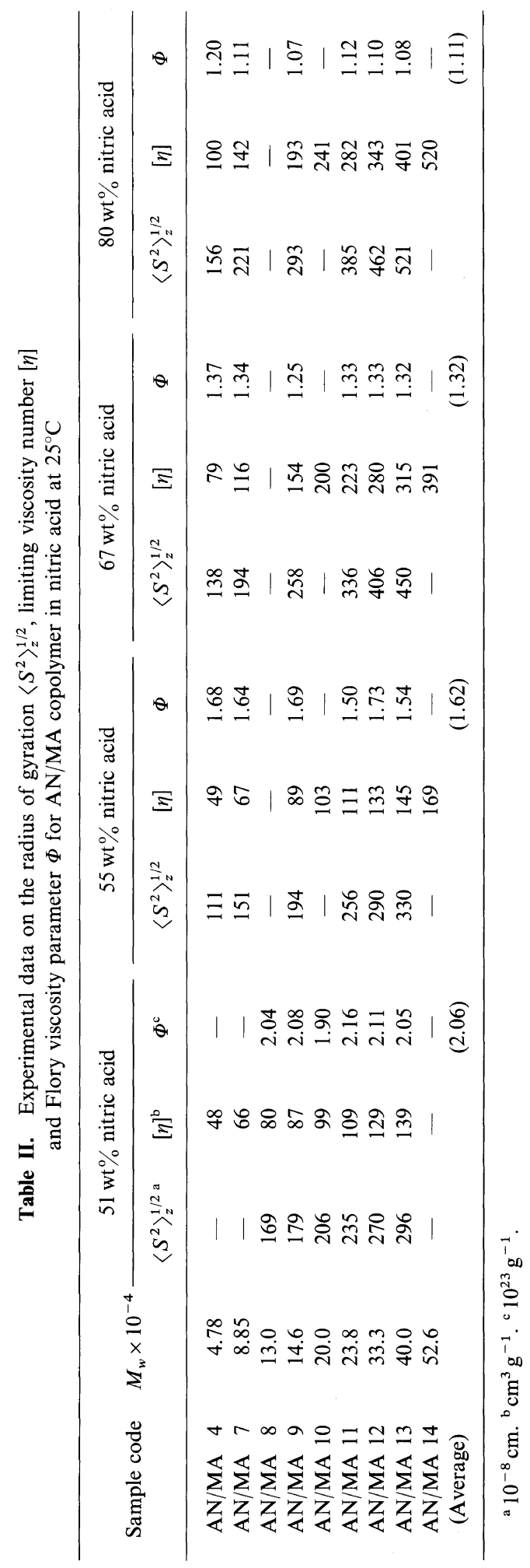




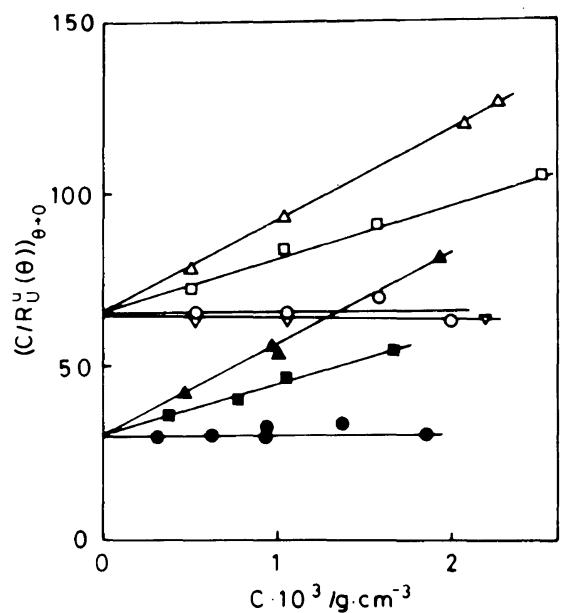

Figure 2. Plots of $\left(C / R_{\mathrm{U}}^{\mathrm{u}}(\theta)\right)_{0 \rightarrow 0}$ versus concentration $C$ for the AN/MA copolymer in EC/water mixtures at $25^{\circ} \mathrm{C}$ : unfilled marks, AN/MA $10\left(M_{w}=20.0 \times 10^{4}\right)$; filled marks, AN/MA $12\left(M_{w}=33.3 \times 10^{4}\right)$; triangles, $w_{\mathrm{e}}=87.5 \mathrm{wt} \%$; rectangles, $w_{\mathrm{e}}=85 \mathrm{wt} \%$; circles, $w_{\mathrm{e}}=82.5$ $\mathrm{wt} \%$; reverse triangles, $w_{\mathrm{e}}=81.5 \mathrm{wt} \%$.

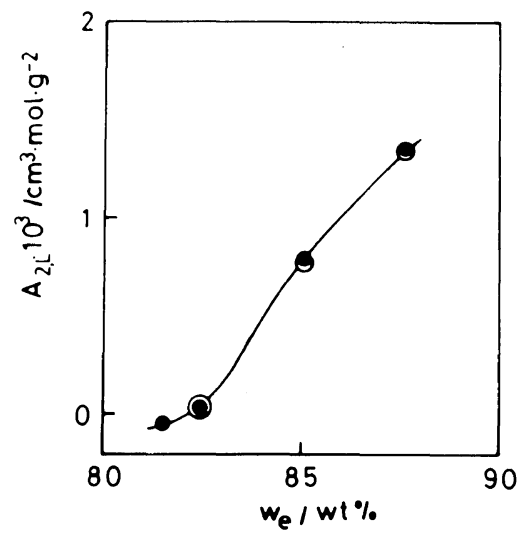

Figure 3. Variation in the second virial coefficient $A_{2, \mathrm{~L}}$ with EC concentration $w_{\mathrm{e}}$ for the AN/MA copolymer in $\mathrm{EC} /$ water mixture at $25^{\circ} \mathrm{C}$ : filled mark, AN/MA 10 $\left(M_{w}=20.0 \times 10^{4}\right)$; unifilled marks, AN/MA $12\left(M_{w}=\right.$ $\left.33.3 \times 10^{4}\right)$.

interaction parameter B estimated by method $2 \mathrm{C}$ or method 2E described below are also shown. From Figure 4 it is evident that Flory's theta conditions can be obtained with $51 \mathrm{wt} \%$ aqueous nitric acid at $25^{\circ} \mathrm{C}$.

Log-log plots of $[\eta] v s . M_{w}$ for the AN/MA copolymer in DMF, and EC/water mixture, and aqueous nitric acid of different compositions at $25^{\circ} \mathrm{C}$ are shown in Figure $5 \mathrm{a}$ and $\mathrm{b}$. From these

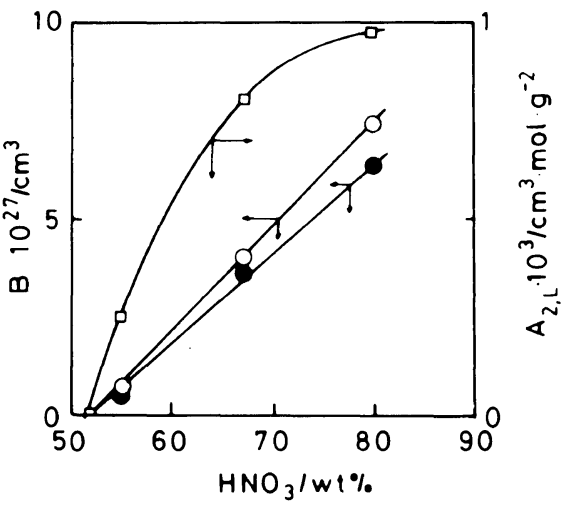

Figure 4. Variation in the second virial coefficient $A_{2, \mathrm{~L}}$ and long-range interaction parameter $B$ (estimated by method 2C and 2E) of the AN/MA copolymer with nitric acid concentration. $\square, A_{2, \mathrm{~L}}$; AN/MA $11\left(M_{w}=\right.$ $23.3 \times 10^{4}$ ); $\bigcirc, B$ by method $2 \mathrm{C} ; \quad, B$ by method $2 \mathrm{E}$, in which the experimental $\Phi$ value corrected for the excluded volume effect $\left(\Phi / \alpha_{s}^{-0.57}\right)$ was used.

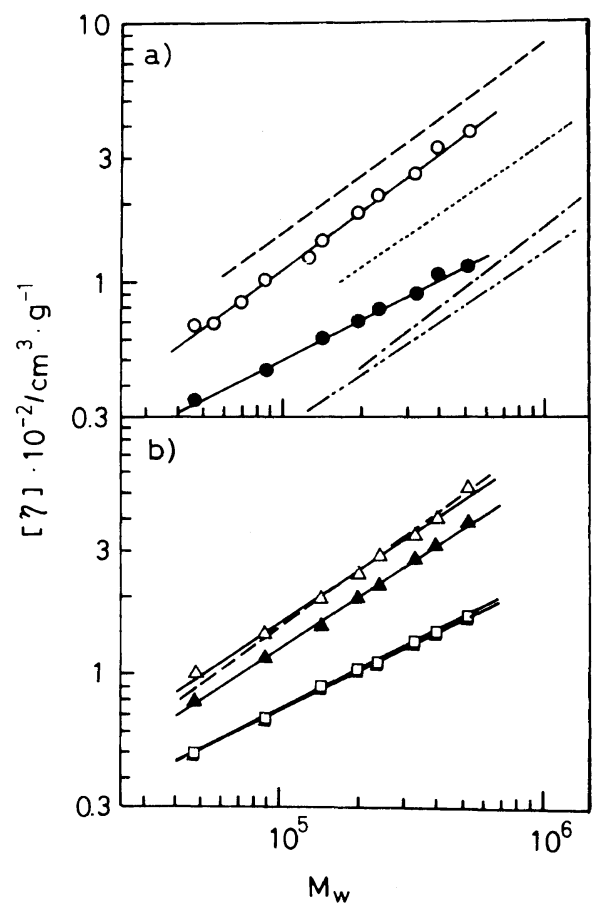

Figure 5. Log-log plots of limiting viscosity number [ $\eta$ ] versus weight-average molecular weight $M_{w}$ for AN/ MA copolymer solutions: a) $\bigcirc$, the AN/MA copolymer in DMF;, $\mathrm{EC} /$ water $\left(w_{\mathrm{e}}=82.5 \mathrm{wt} \%\right)$ mixture; broken line, PAN in DMF; ${ }^{6}$ dotted line, the AN/MA copolymer in $\mathrm{DMF}^{11}$; dot-dash line, PMA in butanone ${ }^{12}$; dot-dotdash line, PMMA in DMF. ${ }^{23}$ b) $\triangle, 80 \mathrm{wt} \% \mathrm{HNO}_{3} ; \boldsymbol{\Delta}$, $67 \mathrm{wt} \% \mathrm{HNO}_{3} ; \square, 55 \mathrm{wt} \% \mathrm{HNO}_{3} ; \mathbf{\square}, 51 \mathrm{wt} \% \mathrm{HNO}_{3}$; broken line, PAN in $60 \mathrm{wt} \% \mathrm{HNO}_{3}{ }^{10}$ 
Table III. $K_{\mathrm{m}}$ and $a$ in the Mark-Houwink-Sakurada equations and $K_{\gamma}$ and $\gamma$ in the relations between $\left\langle S^{2}\right\rangle_{z}^{1 / 2}$ and $M_{w}$ for

AN/MA copolymer in various solvents at $25^{\circ} \mathrm{C}$

\begin{tabular}{|c|c|c|c|c|}
\hline \multirow{2}{*}{ Solvent } & \multirow{2}{*}{$\frac{K_{\mathrm{m}} \times 10^{2}}{\mathrm{~cm}^{3} \mathrm{~g}^{-1}}$} & \multirow{2}{*}{$a$} & $K_{\gamma} \times 10^{8}$ & \multirow{2}{*}{$\gamma$} \\
\hline & & & $\mathrm{cm}$ & \\
\hline DMF & 2.13 & $0.74_{3}$ & $0.21_{3}$ & 0.58 \\
\hline $\mathrm{EC} /$ water $\left(w_{\mathrm{e}}=82.5 \mathrm{wt} \%\right)$ & 15.2 & $0.50_{2}$ & $0.35_{1}$ & 0.50 \\
\hline $51 \mathrm{wt} \%$ nitric acid & 21.5 & $0.50_{2}$ & $0.45_{5}$ & 0.50 \\
\hline $55 \mathrm{wt} \%$ nitric acid & 19.5 & $0.51_{3}$ & $0.46_{0}$ & 0.51 \\
\hline $67 \mathrm{wt} \%$ nitric acid & 5.88 & $0.66_{5}$ & $0.34_{5}$ & 0.55 \\
\hline $80 \mathrm{wt} \%$ nitric acid & 6.22 & $0.68_{0}$ & $0.35_{9}$ & 0.56 \\
\hline
\end{tabular}

figures, the parameters $K_{\mathrm{m}}$ and $a$ in the MarkHouwink-Sakurada (MHS) equation.

$$
[\eta]=K_{\mathrm{m}} M^{a}
$$

have been evaluated by the least-squares method, and the results are summarized in Table III.

The MHS parameters in Table III were obtained with the data for the samples with $M_{w} / M_{n}=1.21-$ 1.40 (average, 1.30), and thus can be corrected for polydispersity ${ }^{9}$ if the Schulz-Zimm distribution of molecular weight is assumed. The results are, for example,

$$
[\eta]=2.24 \times 10^{-2} M^{0.74} \text { in DMF at } 25^{\circ} \mathrm{C}
$$

and

$[\eta]=0.164 M^{0.5}$ in EC/water mixture at $25^{\circ} \mathrm{C}(\mathrm{b})$

Kamide et al. ${ }^{5}$ established the following MHS equation for PAN, prepared by a conventional redox polymerization, in $\mathrm{DMF}$ at $20^{\circ} \mathrm{C}$.

$$
[\eta]=4.66 \times 10^{-2} M_{w}^{0.71} \text { in DMF at } 20^{\circ} \mathrm{C}
$$

The parameter $K_{\mathrm{m}}$ in eq c can be converted to that at $25^{\circ} \mathrm{C}$, using the temperature dependence data of $[\eta]$ for the PAN/DMF system, ${ }^{10}$ the result was $K_{\mathrm{m}}=$ $4.56 \times 10^{-2}$. In Figure $5 \mathrm{a}$, eq $\mathrm{c}$ is represented by a broken line. Introduction of $8 \mathrm{wt} \% \mathrm{MA}$ into $\mathrm{AN}$ thus reduces $[\eta]$ in DMF by about $30 \%$. Figure 5 a includes the literature data for copolymers of acrylonitrile and methyl methacrylate (AN/MMA, 32.8/67.2, wt/wt) in DMF, ${ }^{11}$ poly(methyl methacrylate) (PMMA) in DMF, ${ }^{11}$ and poly(methyl acrylate) (PMA) in butanone. ${ }^{12} \mathrm{~A}$ discernible decrease in AN content in the AN/MA copolymers invariably results in the lowering of $[\eta]$ when compared at the same $M_{w}$.
As expected, the exponent $a$ in eq 4 is equal to 0.5 for the EC/water mixture with $w_{\mathrm{e}}=8.25 \mathrm{wt} \%$ and 51 $\mathrm{wt} \%$ nitric acid at $25^{\circ} \mathrm{C}$. For PAN prepared by conventional redox polymerization (redox PAN), Kamide $e t a l .{ }^{13}$ found $a=0.5$ in the mixture of EC and water with $w_{\mathrm{e}}=85 \mathrm{wt} \%$ at $26^{\circ} \mathrm{C}$ and obtained,

$$
[\eta]=0.282 M_{w}^{0.50}
$$

More recently, Kamide and Terakawa ${ }^{14}$ prepared PAN by gammer-ray irradiation of an urea-canal complex of AN ( $\gamma$-PAN) and obtained the following MHS equation in $\mathrm{EC}$ at $60^{\circ} \mathrm{C}$.

$$
[\eta]=0.295 M_{w}^{0.50}
$$

Nuclear magnetic resonance spectra revealed that the stereoregularity of $\gamma$-PAN is appreciably different from the redox PAN and that the former consists of $75 \%$ isotactic diad and $25 \%$ syndiotactic diad and the latter consists of $50 \%$ isotactic diad and $50 \%$ syndiotactic diads. ${ }^{4,15}$ The MHS equation for the AN/MA copolymer in the EC/water mixture with $w_{\mathrm{e}}=82.5 \mathrm{wt} \%$ at $25^{\circ} \mathrm{C}$ should be compared with eq $\mathrm{d}$ for PAN.

[ $\eta$ ] at constant $M_{w}$ and $a$ increased markedly with an increase in the concentration of nitric acid. Moreover, $[\eta]$ in aqueous nitric acid showed a very weak positive temperature dependence. The values of the temperature coefficient of $\ln [\eta], \mathrm{d} \ln [\eta] / \mathrm{d} T$, were $0.26,0.20$, and $0.15 \mathrm{~cm}^{3} \mathrm{~g}^{-1} \mathrm{~K}^{-1}$ in 55,67 , and $80 \mathrm{wt} \%$ nitric acid, respectively.

Fujisaki and Kobayashi ${ }^{10}$ established the following MHS equation for PAN in $60 \mathrm{wt} \%$ aqueous nitric acid at $20^{\circ} \mathrm{C}$ :

$$
[\eta]=3.07 \times 10^{-2} M_{w}^{0.74}
$$




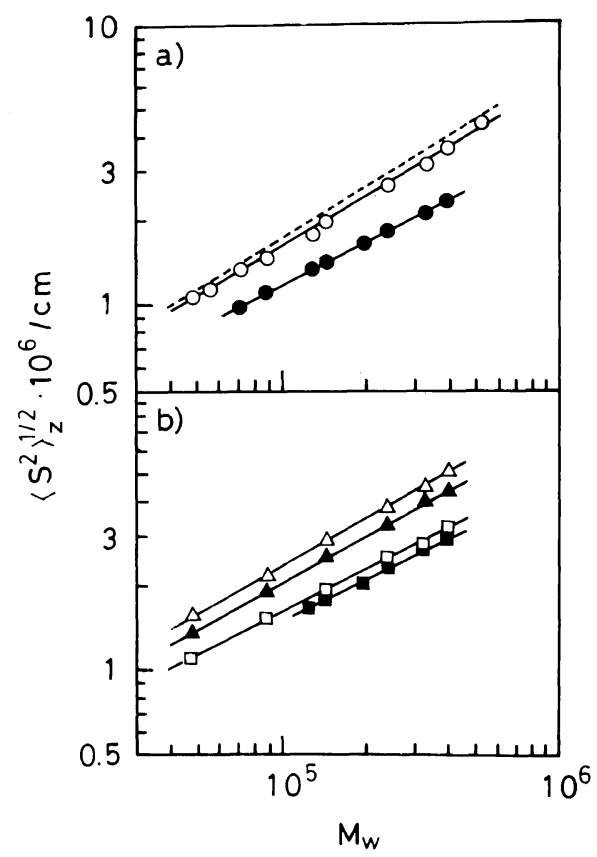

Figure 6. Plots of the radius of gyration $\left\langle S^{2}\right\rangle_{z}^{1 / 2}$ as a function of weight-average molecular weight $M_{w}$ for AN/MA copolymer fractions, a) $\bigcirc, \mathrm{DMF} ; \mathrm{EC} /$ water $\left(w_{\mathrm{e}}=82.5 \mathrm{wt}^{\circ}\right)$ mixture; dotted line, $\mathrm{PAN}$ in $\mathrm{DMF}^{6}$ at $20^{\circ} \mathrm{C}$. b) $\triangle, 80 \mathrm{wt} \% \mathrm{HNO}_{3} ; \boldsymbol{\Delta}, 67 \mathrm{wt} \% \mathrm{HNO}_{3} ; \square, 55$ $\mathrm{wt} \% \mathrm{HNO}_{3} ; \boldsymbol{\square}, 51 \mathrm{wt} \% \mathrm{HNO}_{3}$.

This exponent 0.74 is comparable to that in DMF and is much higher than those $(0.50-0.68)$ for the AN/MA copolymer. Equation $f$ is shown as a broken line in Figure 5b for comparison and indicates that PAN has a higher $[\eta]$ than the AN/MA copolymer in nitric acid. It should be noted that PMA swells only somewhat and does not dissolve in nitric acid at room temperature.

Figure 6 displays the molecular weight dependence of $\left\langle S^{2}\right\rangle_{z}^{1 / 2}$ for the AN/MA copolymer in various solvents at $25^{\circ} \mathrm{C}$. In the figure, the data of Kamide et al. ${ }^{6}$ for PAN in DMF are included as a dotted line. The magnitude of $\left\langle S^{2}\right\rangle_{z}^{1 / 2}$ of the AN/ MA copolymer is $2 \%$ smaller than that of PAN in DMF. $\left\langle S^{2}\right\rangle_{z}^{1 / 2}$ is empirically related to $M_{w}$ by

$$
\left\langle S^{2}\right\rangle_{z}^{1 / 2}=K_{\gamma} M_{w}{ }^{\gamma}
$$

The parameters $K_{\gamma}$ and $\gamma$ in eq 5 for the AN/MA copolymer solutions were determined by the leastsquares method, and the results are summarized in Table III. It is seen that the AN/MA copolymer

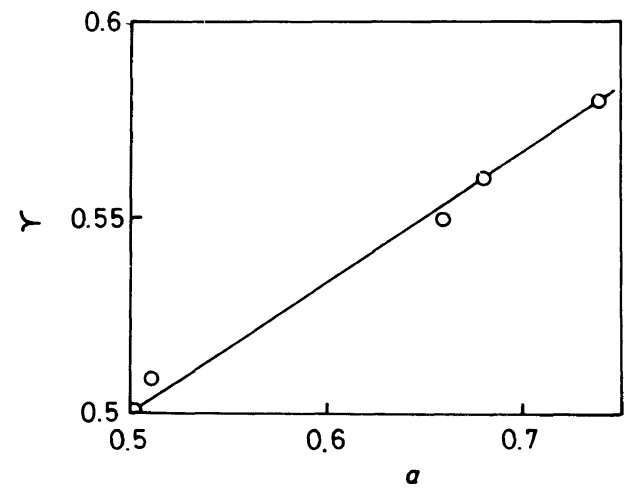

Figure 7. Relations between $\gamma$ in eq 5 and $a$ in eq 4 for AN/MA copolymer solutions: Full line, theoretical curve calculated by eq 8 .

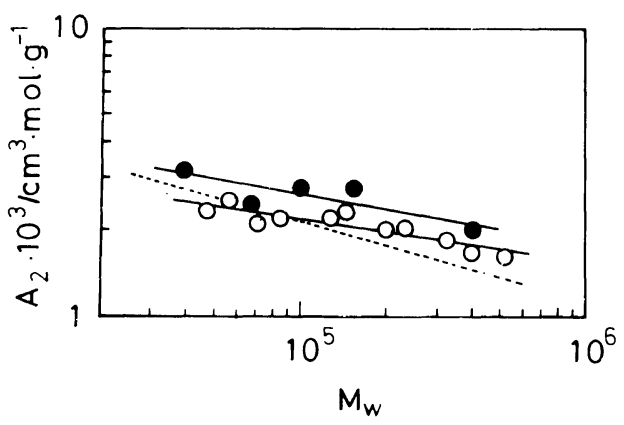

Figure 8. Molecular weight dependence of the second virial coefficient $A_{2}$ for the AN/MA copolymer in DMF at $25^{\circ} \mathrm{C}$. Unfilled circles, $A_{2, \mathrm{~L}}$ by light scattering; filled circles, $A_{2,0}$ by membrane osmometry; dotted line, PAN in DMF by light scattering. ${ }^{6}$

behaves as a gaussian chain in the Flory's theta solvents and that this polymer in $51 \mathrm{wt} \%$ aqueous nitric acid is more expanded than that in the EC/ water mixture. The radius of gyration is greater in more concentrated aqueous nitric acid.

The molecular weight dependence of $\left\langle S^{2}\right\rangle_{z}^{1 / 2}$ is somewhat stronger at a higher nitric acid concentration. The dissolved state of the AN/MA copolymer in aqueous nitric acid as yet remains unclear, and consideration on this problem is beyond the scope of this paper.

When the molecular weight dependence of Flory's viscosity parameter $\Phi$ is ignored, the parameter $\gamma$ in eq 5 is related to the exponent $a$ by $^{16}$

$$
\gamma=(1+a) / 3
$$

Figure 7 illustrates the relation between $\gamma$ and $a$. It is 
seen that the experimental points fit the linear relation predicted by eq 6 .

Figure 8 shows the molecular weight dependence of $A_{2}$, determined by light scattering (open circles) and membrane osmometry (closed circles), for the $\mathrm{AN} / \mathrm{MA}$ copolymer in DMF at $25^{\circ} \mathrm{C}$. The following empirical relations can be derived:

$$
\begin{aligned}
& A_{2, \mathrm{~L}}=1.19 \times 10^{-2} M_{w}^{-0.15} \\
& \quad \text { in DMF at } 25^{\circ} \mathrm{C} \\
& A_{2, \mathrm{O}}=1.90 \times 10^{-2} M_{w}^{-0.17}
\end{aligned}
$$

$$
\text { in } \mathrm{DMF} \text { at } 25^{\circ} \mathrm{C}
$$

The second virial coefficients $A_{2, \mathrm{o}}$ are about $25 \%$ larger than those by light scattering. In the previous paper, ${ }^{6}$ we obtained for PAN in DMF

$$
\begin{gathered}
A_{2, \mathrm{~L}}=4.94 \times 10^{-2} M_{w}^{-0.29} \\
\text { in DMF at } 20^{\circ} \mathrm{C} \text { by LS }
\end{gathered}
$$

Equation $i$ is shown as a broken line in Figure 8. It is seen that the molecular weight dependence of $A_{2}$ becomes less pronounced by the introduction of $\mathrm{MA}$ into the AN homopolymer.

The values of Flory's viscosity parameter $\Phi\left(\equiv[\eta] M_{w} q_{w, z} / 6^{3 / 2}\left\langle S^{2}\right\rangle_{z}^{3 / 2} ; q_{w, z}=\right.$ correction factor for polydispersity) for the AN/MA copolymer in $\mathrm{DMF}$, the EC/water mixture with $w_{\mathrm{e}}=82.5 \mathrm{wt} \%$, and aqueous nitric acid are listed in Tables I and II. Here, $q_{w, z}$ was calculated assuming the SchulzZimm distribution, and the $\Phi$ values in the EC/ water mixture and aqueous nitric acid were calculated using the $M_{w}$ values obtained in DMF. It is seen that the $\Phi$ values corrected for polydispersity remain nearly constant, giving on the average $(2.5 \pm 0.1) \times 10^{23}$ and $(2.9 \pm 0.1) \times 10^{23}$ for DMF and the EC/water mixture (theta solvent), respectively. These values are comparable to those obtained for other flexible polymers in good and theta solvents, respectively. The values of $\Phi$ in aqueous nitric acid were significantly smaller than those in DMF and the EC/water mixture, decreasing with an increase in nitric acid content. It should be noted that the $\Phi$ value in $51 \mathrm{wt} \%$ nitric acid, which can be regarded as $\Phi_{0}(\infty)$ (i.e., $\Phi$ in a theta solvent at the non-draining limit), is only $70 \%$ of the theoretical value $\left(2.87 \times 10^{23}\right)$.

The unperturbed chain dimension $A\left[=\left(\left\langle R^{2}\right\rangle_{0} /\right.\right.$ $M)^{1 / 2} ;\left\langle R^{2}\right\rangle_{0}^{1 / 2}$ is the mean-square end-to-end distance in the unperturbed state] for a polar polymer dissolved in polar solvents is expected to depend markedly on the solvent. Thus, the measurement of $\left\langle S^{2}\right\rangle^{1 / 2}$ only in a theta solvent $(\operatorname{method} 2 \mathrm{~A}$, see eq 7$)$ is apparently insufficient to determine $\mathrm{A}$, and careful considerations must be made on the applicability of the methods for estimating $A$ from data obtained in non-theta solvents.

In this article, the following methods were employed for evaluating $A$ :

\section{Method $2 A$}

Measurement of $\left\langle S^{2}\right\rangle_{0}^{1 / 2}$ of a polymer in Flory's theta solvent allows $A$ to be determined from

$$
A=6^{1 / 2}\left(\left\langle S^{2}\right\rangle_{0} / M\right)^{1 / 2}
$$

where the subscript zero indicates the unperturbed state.

\section{Method $2 B$}

$\left\langle S^{2}\right\rangle_{0}^{1 / 2}$ is calculated from the experimental value of $\left\langle S^{2}\right\rangle^{1 / 2}$ obtained in a good solvent together with the expansion factor $\alpha_{\mathrm{s}}$ estimated from the penetration function $\Psi$ defined by $\Psi=A_{2} M_{\mathrm{w}}{ }^{2} /$ $\left(4 \pi^{3 / 2} N_{\mathrm{A}}\left\langle S^{2}\right\rangle_{w}^{3 / 2}\right)$, by the equation described before. ${ }^{17}$ The $A$ value can then be obtained by eq 7 .

$$
\begin{aligned}
& \text { Method } 2 C \text { (Baumann Plot) }{ }^{18} \\
& \qquad\left\langle S^{2}\right\rangle^{3 / 2} / M^{3 / 2}=A^{3} / 6^{3 / 2}+\left(1 / 4 \pi^{3 / 2}\right) B M^{1 / 2}
\end{aligned}
$$

Here, $\mathrm{B}$ is a long-range interaction parameter.

\section{Method 2E (Stockmayer-Fixman Plot $)^{19}$}

$$
[\eta] / M^{1 / 2}=K+2(3 / 2 \pi)^{3 / 2} \Phi_{0}(\infty) B M^{1 / 2}
$$

with

$$
K=\Phi_{0}(\infty) A^{3}
$$

The values of $\left\langle S^{2}\right\rangle_{z}^{1 / 2}$ in Tables I and II were converted to $\left\langle S^{2}\right\rangle_{w}^{1 / 2}$, using the experimental values of $M_{w} / M_{n}$ and assuming the Schulz-Zimm molecular weight distribution for each fraction.

Method 2A was applied to the AN/MA copolymer in the two theta solvents. The results are listed in Table IV. The $A$ value in the EC/water mixture is about $10 \%$ smaller than that in $51 \mathrm{wt} \%$ aqueous nitric acid. This significant difference suggests that the dissolved states of the polymer in these two mixtures should be different as a result of a specific effect of nitric acid on the polymer chain.

For the AN/MA copolymer in DMF, the func- 
Table IV. Unperturbed chain dimension $A$, long-range interaction parameter $B$, conformation parameter $\sigma$ and characteristic ratio $C_{\infty}$ of $\mathrm{AN} / \mathrm{MA}$ copolymer in various solvents

\begin{tabular}{|c|c|c|c|c|c|c|c|c|c|}
\hline \multirow{2}{*}{ Solvent } & \multicolumn{5}{|c|}{$A \times 10^{8} / \mathrm{cm}$} & \multicolumn{2}{|c|}{$B \times 10^{27} / \mathrm{cm}^{3}$} & \multirow{2}{*}{$\sigma$} & \multirow{2}{*}{$C_{\infty}$} \\
\hline & $2 \mathrm{~A}$ & $2 \mathrm{~B}$ & $2 \mathrm{C}$ & $2 \mathrm{E}$ & $\begin{array}{l}\text { most } \\
\text { probable }\end{array}$ & $2 \mathrm{C}$ & $2 \mathrm{E}$ & & \\
\hline DMF & - & - & 0.93 & 0.88 & 0.93 & 2.89 & 2.50 & 2.25 & 10.1 \\
\hline $\mathrm{EC} /$ water $\left(w_{\mathrm{e}}=82.5 \mathrm{wt} \%\right)$ & 0.86 & - & - & - & 0.86 & 0 & 0 & 2.08 & 8.7 \\
\hline $51 \mathrm{wt} \%$ nitric acid & 1.11 & - & - & - & 1.11 & 0 & 0 & 2.68 & 14.5 \\
\hline $55 \mathrm{wt} \%$ nitric acid & - & 1.12 & 1.11 & 1.11 & 1.12 & 0.70 & 0.42 & 2.69 & 14.6 \\
\hline $67 \mathrm{wt} \%$ nitric acid & - & 1.30 & 1.29 & 1.25 & 1.30 & 4.07 & 3.71 & 3.13 & 19.7 \\
\hline $80 \mathrm{wt} \%$ nitric acid & - & 1.55 & 1.42 & 1.42 & 1.49 & 7.40 & 6.47 & 3.59 & 25.9 \\
\hline
\end{tabular}

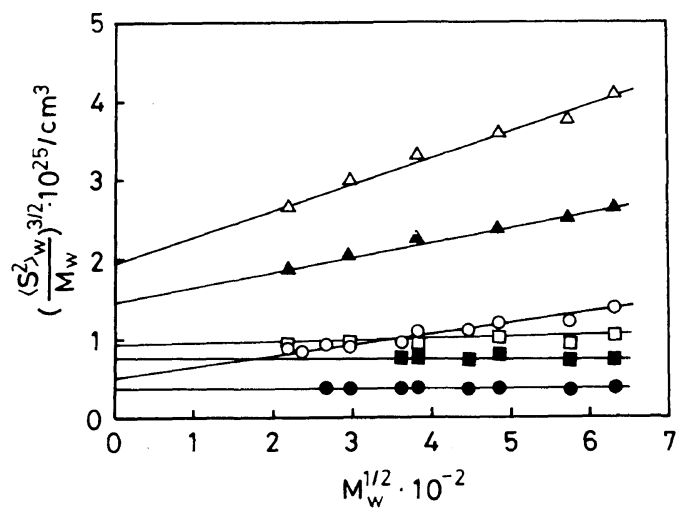

Figure 9. Baumann plot (method $2 \mathrm{C}$ ) for the AN/MA copolymer at $25^{\circ} \mathrm{C}$. $\bigcirc, \mathrm{DMF} ; \mathrm{O}, \mathrm{EC} /$ water $\left(w_{\mathrm{e}}=82.5\right.$ wt $\%$ ) mixture; $\triangle, 80 \mathrm{wt} \% \mathrm{HNO}_{3} ; \Delta, 67 \mathrm{wt} \% \mathrm{HNO}_{3} ; \square$, $55 \mathrm{wt} \% \mathrm{HNO}_{3} ; \mathbf{\square}, 51 \mathrm{wt} \% \mathrm{HNO}_{3}$. tion $\Psi$ was larger than 0.41 , which is too large for a definite estimation of $\alpha_{\mathrm{s}}$. Therefore, method 2B was not applicable to this system.

Figures 9 and 10 show the Baumann plot and the Stockmayer-Fixman plot for the AN/MA copolymer in various solvents. Both plots are represented by straight lines, even at high molecular weights, in agreement with eq 8 and 9 . The $A$ values obtained from the intercept are listed in Table IV, which indicates that method $2 \mathrm{~B}$ and $2 \mathrm{C}$ yield almost the same $A$ values. In applying method $2 \mathrm{E}$, the experimental $\Phi$ values were corrected for the excluded volume effect $\left(\Phi / \alpha_{s}^{-0.57}\right)$ and taken to be $\Phi_{0}(\infty)$ for nitric acid solutions.

For the AN/MA copolymer in EC/water and in DMF, the values of $A \times 10^{8} / \mathrm{cm}$ obtained by the thermodynamic approach were 0.86 for the former solvent and 0.93 for the latter solvent.

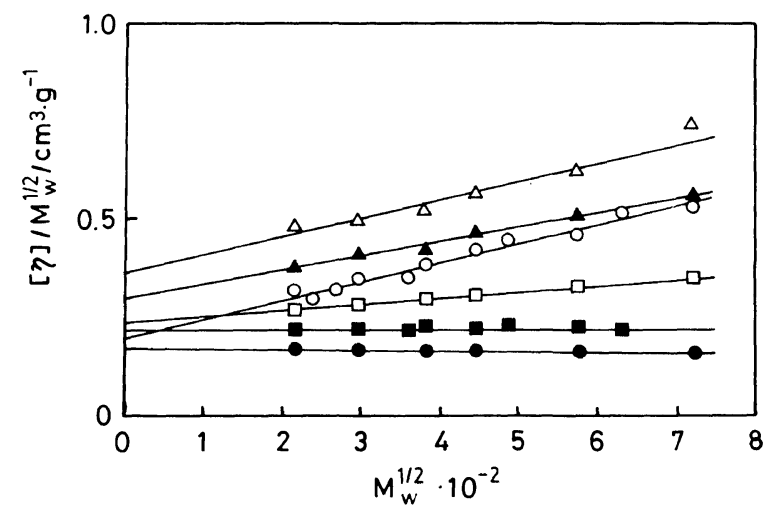

Figure 10. Stockmayer-Fixman plot (method $2 \mathrm{E}$ ) for the AN/MA copolymer at $25^{\circ} \mathrm{C}$. Marks have the same meaning as those in Figure 9. 
For the AN/MA copolymer solution in nitric acid the use of $\Phi / \alpha_{\mathrm{s}}^{-0.57}$ for $\Phi_{0}(\infty)$ in method $2 \mathrm{E}$ gave almost the same $A$ values as those by method 2B and $2 \mathrm{C}$. This suggests strongly some significant variation of $\Phi_{0}(\infty)$ with nitric acid concentration.

The most probable $\mathrm{A}$ is the average of the values from the thermodynamic approaches (method 2A, $2 B$, and $2 \mathrm{C}$ ) as given in sixth column of Table IV. This table also gives the $B$ values estimated from the slopes of the plots in Figures 9 and 10. It is seen that the $B$ values by method $2 \mathrm{E}$ are in good agreement with those by the thermodynamic approaches (method 2C).

The $A$ values in Table IV show a significant dependence on the kind of solvent; these are larger for better solvents characterized by larger $B$. This behavior of $A$ may be explained in terms of the solvation, as is the case of cellulose derivatives. ${ }^{17,20-22}$ The temperature dependence of $A$ in nitric acid is negligible within experimental error.

The unperturbed chain dimension $A_{\mathrm{f}}$ of a hypothetical AN/MA chain with free internal rotation can be expressed by ${ }^{23}$

$$
A_{\mathrm{f}}^{2}=\frac{n}{M}\left[-b^{2}+2 l^{t}\left(1-\langle T\rangle^{-1} l\right)\right]
$$

with

$$
\langle T\rangle=w_{\mathrm{a}}\left\langle T_{\mathrm{a}}\right\rangle+\left(1-w_{\mathrm{a}}\right)\left\langle T_{\mathrm{m}}\right\rangle
$$

Here, $n$ is the number of bonds in the chain, $b$ is the bond length, $l$ is the bond vector, $l^{t}$ is the transpose bond vector, $T_{\mathrm{a}}$ and $T_{\mathrm{m}}^{*}$ are the orthogonal transformation matrices of $\mathrm{AN}$ and MA bonds, the angle bracket is the statistical-mechanical average over all possible configurations of the chain, and $w_{\mathrm{a}}$ is the weight fraction of AN.

The bond angles for AN and MA bonds can be taken as $\theta=109^{\circ}$. Thus, eq 11 can be rewritten as

$$
A_{\mathrm{f}}^{2}=w_{\mathrm{a}} A_{\mathrm{a}, \mathrm{f}}^{2}+\left(1-w_{\mathrm{a}}\right) A_{\mathrm{m}, \mathrm{f}}^{2}
$$

where $A_{\mathrm{a}, \mathrm{f}}$ and $A_{\mathrm{m}, \mathrm{f}}$ denote the $A_{\mathrm{f}}$ of PAN and PMA, respectively. Putting $w_{\mathrm{a}}=0.92, A_{\mathrm{a}, \mathrm{f}}=$ $0.442 \times 10^{-8} \mathrm{~cm}$ and $A_{\mathrm{m}, \mathrm{f}}=0.332 \times 10^{-8} \mathrm{~cm}$ into eq 13, we obtain $0.414 \times 10^{-8} \mathrm{~cm}$ for $A_{\mathrm{f}}$.

The conformation parameter $\sigma$ and the characteristic ratio $C_{\infty}$ are expressed by

$$
\begin{aligned}
& \sigma=\left(A^{2} / A_{\mathrm{f}}^{2}\right)^{1 / 2} \\
& C_{\infty}=A^{2} M_{\mathrm{b}} / l^{2}
\end{aligned}
$$

where $M_{\mathrm{b}}$ is the mean molecular węight per skeletal

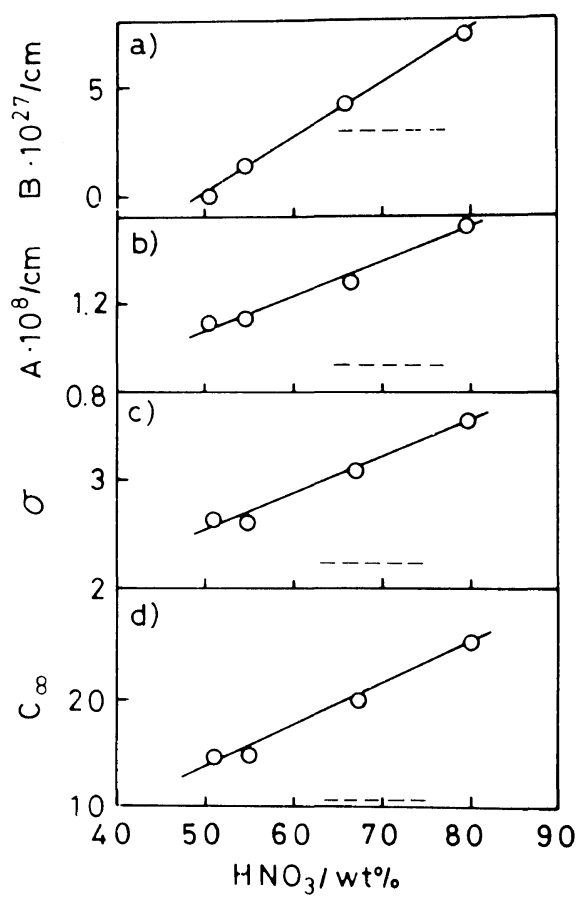

Figure 11. Effect of nitric acid concentration on the short- and long-range interaction parameters $A$ and $B$, the conformation parameter $\sigma$, and the characteristic ratio $C_{\infty}$ for the $\mathrm{AN} / \mathrm{MA}$ copolymer in aqueous nitric acid at $25^{\circ} \mathrm{C}$.

bond and $l$ is the mean bond length. The values of $\sigma$ and $C_{\infty}$ calculated using the most probable $A$ values are tabulated in Table IV.

Figure 11 shows the changes in $\mathrm{B}, \mathrm{A}, \sigma$, and $C_{\infty}$ with the concentration of nitric acid. In the figure, the corresponding values in DMF are also shown by broken lines. It is seen that the short- and long-range interaction parameters A and B increase noticeably with an increase in nitric acid concentration. In more concentrated nitric acid solutions the AN/MA copolymer becomes more rigid and much more expanded by the volume effect. Comparison of the $B$ values shows that DMF is apparently a better solvent for the AN/MA copolymer than aqueous nitric acid containing less than $60 \mathrm{wt} \%$.

In the previous paper, ${ }^{2}$ it was shown that the amorphous phase of solid polyacrylonitrile coagulated from a $67 \mathrm{wt} \%$ aqueous nitric acid solution consists of closely packed polymer molecules, giving a higher glass transition temperature than the amorphous phase cast from a DMF solution, This 


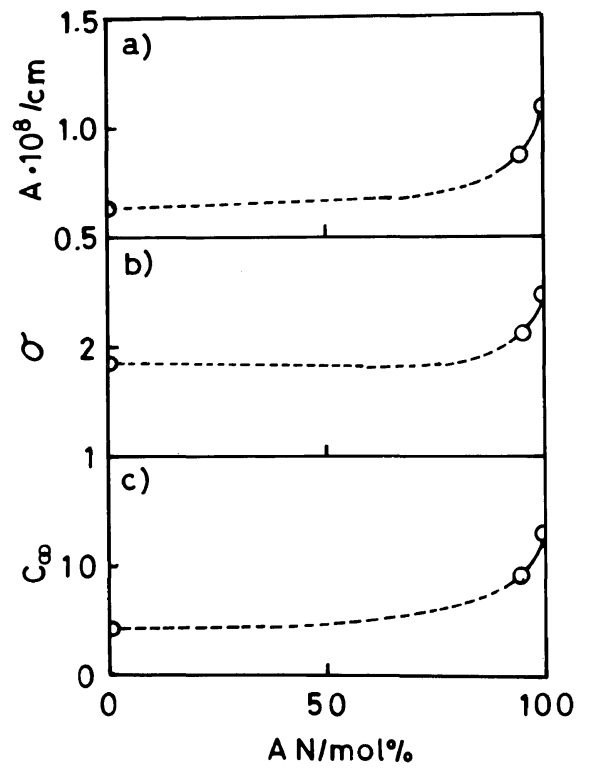

Figure 12. Effect of the $\mathrm{AN}$ content in the AN/MA copolymer on the short-range interaction parameter $A$, the conformation parameter $\sigma$ and the characteristic ratio $C_{\infty}$.

difference was also observed to AN/MA copolymers, and may be accounted for the flexibility of the AN/MA copolymer which is less in $67 \mathrm{wt} \%$ nitric acid solution than in DMF.

Using the MHS equation for Flory's theta solvent and method $2 \mathrm{E}$, we estimated $A$ and the related parameters from literature data for PAN in $\mathrm{DMF}^{5}$ and for PMA in isoamyl acetate. ${ }^{12}$ Figure 12 , which illustrates the relation between $A$ (or $\sigma$ or $C_{\infty}$ ) and AN content for PAN, the AN/MA copolymer and PMA, indicates that the AN/MA copolymer containing $8 \mathrm{wt}^{\%}$ (i.e., $5 \mathrm{~mol} \%$ ) MA is more flexible than PAN in DMF.

Acknowledgement. The authors should like to express their appreciation to Mr. M. Sasaki for his skillful technical assistance.

\section{REFERENCES}

1. G. Coppola, P. Fabbri, and B. Pallesi, J. Appl. Polym. Sci., 16, 2829 (1972).

2. C. Nakayama, K. Kamide, S. Manabe, T. Sakamoto, Sen-i Gakkaishi, 33, T-139 (1977).

3. H. Mark, B. Immergut, and E. H. Immergut, High Polymer XV III, "Copolymerization," Appendix, G. E. Han, Ed., Interscience Pub., New York, 1964.

4. R. Yamadera and M. Murano, J. Polym. Sci., A-1, 5, 1059 (1967).

5. K. Kamide, Y. Miyazaki, and T. Abe, Br. Polym. J., 13, 168 (1981).

6. K. Kamide, H. Kobayashi, Y. Miyazaki, and C. Nakayama, Kobunshi Kagaku, 24, 679 (1967).

7. R. E. Ewart, C. P. Roe, P. Debye, and J. R. McCarteney, J. Chem. Phys., 14, 687 (1964).

8. P. E. Curry, "Inorganic and Theoretical Chemistry," Vol. VIII, Sup. II, Section XXX, A. A. Eldridge et al., Ed., Longmans, Green and Co. Ltd., London, 1967.

9. see, e.g., K. Kamide, "Polymer Engineering," Vol. 4 (I), Soc. Polym. Sci. Japan. Ed., Chijin-shokan, 1965, p 169.

10. Y. Fujisaki, and H. Kobayashi, Kobushi Kagaku, 19, 81 (1962).

11. Y. Shimura, Bull. Chem. Soc. Jpn., 40, 273 (1967).

12. H. Matsuda, K. Yamada, and H. Inagaki, J. Polym. Sci., $A-7,609$ (1969).

13. K. Kamide, K. Fujii, and H. Kobayashi, Makromol. Chem., 117, 190 (1968).

14. K. Kamide and T. Terakawa, Makromol Chem., 155, 25 (1972).

15. K. Matsuzaki, T. Uryu, M. Okada, H. Shiroki, J. Polym. Sci., A-1, 6, 1475 (1968).

16. J. E. Voeks, J. Polym. Sci., 36, 333 (1959).

17. K. Kamide and Y. Miyazaki, Polym. J., 10, 409 (1978).

18. H. Baumann, J. Polym. Sci., Polym. Lett., 3, 1069 (1965).

19. W. H. Stockmayer and M. Fixman, J. Polym. Sci., Part C, 1, 137 (1963).

20. K. Kamide, T. Terakawa, and Y. Miyazaki, Polym. J., 11, 285 (1979).

21. K. Kamide, Y. Miyazaki, and T. Abe, Polym. J., 11, 523 (1979).

22. K. Kamide, M. Saito, and T. Abe, Polym. J., 13, 421 (1981).

23. see, for example, P. J. Flory, "Statistical Mechanics of Chain Molecules," John Wiley \& Sons, New York, 1969. 